\title{
Pollack, Aaron (2008), Levantamiento K'iche' en Totonicapán, 1820: Los lugares de las políticas subalternas, Guatemala: Avancso.
}

U

Tn año antes de declararse la independencia, varias comunidades de la provincia de Totonicapán, en el altiplano occidental de Guatemala, se sublevaron contra el régimen colonial español. La causa inmediata del levantamiento fue el intento del monarca Fernando VII de reimponer el pago del tributo en 1816, impuesto que era pagado exclusivamente por las comunidades indígenas, y que había sido abolido por las Cortes de Cádiz en 1811.

Al intentar las autoridades del reino efectuar la recaudación, un buen número de comunidades, lideradas por un grupo de indígenas k'iche's del pueblo de San Miguel Totonicapán, la capital de la provincia, rehusaron hacer los pagos. Algunas de ellas justificaban su decisión en razón de la inopia general que aquejaba a los pueblos, resultado de varias epidemias y un terremoto reciente así como de una serie de malas cosechas. Otras insistían en que el rey ya había eliminado la exacción y no creían posible que se hubiera retractado. Es por ello que estaban convencidas de quela supuesta reimposición del impuesto no era más que una estratagema por parte de los comisionados del gobierno, muchos de ellos vecinos ladinos y principales k'iche's, con el perverso fin de arrebatarles sus escasos fondos. De ahí que no sorprenda que los agresivos intentos de dichos individuos por cobrar el impuesto sólo lograra enfurecer aún más a los rebeldes. En consecuencia, a partir de 1819 el desasosiego popular asumió un cariz cada vez más radical, con violentos tumultos y alborotos que ocurrían casi a diario en varios pueblos de la provincia. En estas circunstancias, el gobierno de la audiencia, temeroso de provocar un levantamiento general entre la mayoría indígena, se abstuvo, por el momento, de recurrir a la fuerza, ordenando a sus representantes en la región que se valieran de métodos "dulces y suaves" con el fin de persuadir a los rebeldes de que acataran la orden real.

No obstante, tal política de apaciguamiento produjo el resultado contrario, pues fue interpretada por los grupos desafectos como indicio de debilidad gubernamental, sentimiento que vino a ser reforzado con el anuncio oficial en junio de 1820 sobre la restauración del régimen constitucional en la madre patria. En consecuencia, el 9 de julio, Atanasio Tzul, un k'iche' principal que había surgido como el más destacado jefe de la sublevación, junto con el líder macegual Lucas Aguilar, organizó en la plaza de San Miguel una multitudinaria manifestación, a la cual invitaron a los pueblos vecinos con el fin de celebrar el que veían como magno acontecimiento, pese a la falta de autorización por parte del alcalde mayor José Manuel de Lara. En opinión de los rebeldes, la restauración del 
régimen constitucional venía a confirmar de manera oficial lo que ellos ya daban por sentado, o sea, ya no se pagaba el tributo.

Ese mismo día, Atanasio Tzul fue nombrado gobernador - rey, según la leyenda popular-y Lucas Aguilar presidente, en medio de gran regocijo popular. Dos días después, el alcalde mayor Lara, convencido de que su vida corría peligro, salió huyendo del pueblo con su familia y se refugió en la vecina población de Quetzaltenango. A partir de entonces, Tzul y Aguilar asumieron las riendas del poder político en nombre de Fernando VII, con jurisdicción efectiva sobre el pueblo de San Miguel así como de unas cuantas poblaciones aledañas que brindaron su apoyo al régimen rebelde. Los dirigentes indígenas impartieron justicia, recaudaron fondos y castigaron a los funcionarios k'iche's encargados de cobrar el tributo en años anteriores.

Tras un período de creciente tensión y fallidos esfuerzos por parte de las autoridades regionales de persuadir a los alzados que desistieran de su rebeldía, el gobierno de la audiencia ordenó a Prudencio de Cozar, el comandante militar de Los Altos, que movilizara la tropa miliciana de la región con el fin de suprimir el levantamiento. El 3 de agosto de 1820, las milicias ladinas de Quetzaltenango, Salcajá y San Carlos Sija, marcharon hacia San Miguel Totonicapán y, tras una breve escaramuza a la entrada del pueblo, ocuparon la población de forma aparentemente pacífica, poniendo así fin al gobierno rebelde k'iche'. Por razones poco claras, los indígenas de los pueblos de Momostenango y Santa María Chiquimula, quienes habían figurado entre los más decididos seguidores de Tzul y Aguilar, resolvieron a última hora no acudir al auxilio de San Miguel, contingencia que muy probablemente hizo palpable a los ojos de los líderes la futilidad de todo intento de resistencia.

En marzo de 1821, en parte como respuesta a las peticiones de numerosos indígenas que se habían trasladado a la capital con el fin de implorar clemencia para los prisioneros, el presidente de la audiencia emitió un indulto a favor de los líderes del alzamiento, con excepción de los de San Francisco el Alto, a quienes se acusaba de haber opuesto resistencia armada a la milicia quetzalteca. En los años siguientes, período que coincidió con la transición a la época nacional republicana, muchas de las comunidades de Totonicapán persistieron en su postura rebelde, rehusándose decididamente a pagar cualquier clase de exacción tributaria.

En Levantamiento K'iche' en Totonicapán, 1820, Aaron Pollack, investigador de origen estadounidense y actualmente vinculado al Instituto José María Luis Mora de ciudad de México, presenta una detallada narrativa de los sucesos relativos al levantamiento, junto con un extenso e incisivo análisis de los antecedentes socioeconómicos y políticos del movimiento así como de las consecuencias de la movilización popular en las dos décadas siguientes.

El levantamiento de 1820 fue la última y, a la vez, una de las más importantes manifestaciones de protesta colectiva indígena en la época colonial guatemalteca. Según Pollack, en el contexto regional la sublevación constituyó un significativo esfuerzo por redefinir el poder indígena en Los Altos de Guatemala, al intentar los k'iche's de Totonicapán "crear una forma de política en sus pueblos y más brevemente en el ámbito regional, que habría revertido la tendencia colonial tardía hacia el incremento del poder no indígena en la región, reduciendo a la vez el poder de los nobles indígenas locales" (p. 39). Al mismo tiempo, en opinión de Pollack, el episodio reviste especial relevancia por la manera en que "visibilizó a la gran cantidad de actores políticos en el altiplano occidental de Guatemala", brindando a su vez "un importante punto de ingreso para hacer un análisis sobre la forma en que los actores subalternos influyen en el cambio histórico mediante la planificación y organización" (p. 25).

El libro se compone de una introducción, cinco capítulos y la conclusión. En la introducción, Pollack se 
ocupa de ubicar a la provincia de Totonicapán dentro del contexto histórico guatemalteco, haciendo énfasis en el período de 1800 hasta el presente. Destaca, por un lado, el importante papel que las comunidades mayas han jugado en dicha historia $y$, por el otro, la escasa atención que la experiencia indígena ha recibido en la historiografía nacional. El autor señala cómo dicha historiografía ha tendido "a reducir a los mayas a una masa poco diferenciada, sin estudiar las dinámicas políticas internas de sus pueblos y regiones, ni cómo esas dinámicas respondieron a, o influyeron en, los procesos regionales más amplios" (p. 35).

En esta misma sección del libro, Pollack considera las perspectivas conceptuales que informan su análisis. En su calidad de geógrafo historiador, Pollack utiliza un marco teórico que se distingue por combinar conceptos tanto de la geografía política como de la historia política y económica. El más útil para sus propósitos es el concepto de la construcción relacional de lugar, el cual otorga importancia central a las relaciones entre los lugares en la definición de lo que cualquier lugar dado es. Con base en dicho concepto, Pollack explora las dinámicas al interior de los pueblos involucrados en el levantamiento de 1820, así como los intercambios constantes entre dichos pueblos y sus relaciones con otros lugares, como la ciudad de Guatemala, Quetzaltenango, Ciudad Real, Oaxaca y Madrid. En otras palabras, el uso de tal conceptualización del lugar le permite a Pollack "observar la acción política subalterna" o, en palabras de Florencia Mallon, "excavar la historia política desde abajo”, con el propósito de "aportar al mejor entendimiento y la dignificación de las acciones políticas indígenas en Guatemala” (p. 29).

En los dos primeros capítulos del libro, Pollack desarrolla un sólido análisis del contexto histórico dentro del cual ocurrió el levantamiento de 1820, lo que el autor denomina "un tipo de geografía política y económica" (p. 5l). En el primer capítulo, tras una breve descripción de las estructuras geográficas y político administrativas de la provincia de Totonicapán,
Pollack se concentra en lo que él llama proceso de "modernización etnizada". Según el autor, la sublevación de Totonicapán ocurrió en un contexto de modernización incipiente que tuvo su origen con las reformas administrativas, comerciales, fiscales y militares de los reyes borbónicos en la segunda mitad del siglo XVIII. Explica como tales innovaciones, diseñadas con el fin de ensanchar el alcance de la autoridad borbónica en Los Altos de Guatemala, acabaron por fortalecer la posición de dominio del sector minoritario de españoles y ladinos a expensas de la mayoría indígena. En consecuencia, elementos no indígenas gradualmente asumieron el control de una variedad de puestos burocráticos que les permitió fungir como recaudadores de impuestos, maestros de escuela, administradores de monopolios estatales, vacunadores, así como oficiales y soldados en las milicias disciplinadas. Y quizá más relevante aun en este sentido fue la creación a inicios del siglo XIX de alcaldías de españoles y ladinos en ocho pueblos de indios y el nombramiento de comisionados o tenientes para las once parroquias de la provincia, junto con el otorgamiento de mercedes de tierras baldías y la autorización de compras y arrendamiento de tierra ejidal, todo lo cual le otorgó una importante cuota de poder político, social y económico a los sectores no indígenas de la región. Es así como, al momento de estallar el levantamiento de 1820, ya se había consolidado en la región la estructura bipolar étnica -indígena/ ladino - con su secuela de creciente conflicto étnico y desconfianza mutua. En opinión de Pollack, "al etnizar la modernización, los Borbones acabaron por maximizar el descontento latente entre los indígenas y a su vez redujeron los espacios de cooptación posibles" (p. 46).

En el segundo capítulo, Pollack se ocupa de las dimensiones económicas del proceso de modernización analizado en el capitulo anterior. Desarrollo clave en dicho proceso fue la gradual integración del reino de Guatemala al incipiente sistema capitalista global, con base en la expansión de las exportaciones de añil a los mercados europeos. Pollack describe la manera como la 
región de Los Altos participó indirectamente en dicho proceso, actuando como proveedora de cereales y telas de la tierra a las zonas añileras así como a los mercados de Ciudad de Guatemala, Chiapas y Oaxaca. Pollack examina también la participación de los distintos sectores sociales y étnicos en los procesos de producción y comercialización de dichos productos.

El auge comercial de finales del siglo XVIII, sin embargo, se desplomó a partir de 1800 con la caída de los precios del añil, el incremento en la competencia internacional, los severos trastornos en la transportación marítima ocasionados por las guerras napoleónicas, así como el contrabando de manufacturas británicas. En Los Altos, la crisis tuvo repercusiones profundas al disminuir de manera drástica la demanda de cereales y textiles, productos motores de la economía regional. El levantamiento de 1820, argumenta Pollack, ocurrió entonces en medio de una profunda crisis económica que golpeó con especial fuerza a las comunidades indígenas de la provincia de Totonicapán. Razón por la cual, "la pérdida de ingresos y empleo [...] pudo haber alimentado la oposición política a los impuestos para la iglesia y el tributo que surgió allí después de 1811" (pp. 77).

En el capítulo tres, Pollack analiza los efectos de la aguda crisis política que se desató a partir de 1808 al colapsar la monarquía española como consecuencia de la invasión de los ejércitos napoleónicos. El autor subraya en particular las consecuencias que siguieron a la introducción en 1810 de una serie de leyes y políticas de corte liberal emitidas por las Cortes de Cádiz. Dicha institución parlamentaria había asumido las riendas del poder a nombre del monarca cautivo con el fin principal de coordinar y financiar la campaña militar de liberación nacional y a la vez intentar mantener la estabilidad política dentro del vasto imperio americano.

En Los Altos de Guatemala, dos de las Leyes de Cádiz más impactantes fueron la abolición del tributo así como la eliminación de las raciones y servicios personales que las comunidades indigentes proveían a los curas, medidas sancionadas por las Cortes en 1811 y 1812, respectivamente. El intento de las autoridades de implementar dichos decretos vino a generar, en retrospectiva, un largo período de inestabilidad sociopolítica al interior de las comunidades indígenas de Totonicapán. Al mismo tiempo ocasionó divisiones dentro de las jerarquías civiles y eclesiásticas del reino. La mayoría de los principales y maceguales indígenas se opusieron a obedecer las nuevas leyes debido a que, bajo el nuevo régimen constitucional de igualdad civil, los indígenas quedarían obligados al pago de derechos por servicios eclesiásticos al mismo nivel que los no indígenas, lo cual significaba a fin de cuentas una carga fiscal aún más elevada que antes. Sin embargo, una coalición de dirigentes k'iche's y maceguales en San Miguel Totonicapán, con el apoyo de varios pueblos aledaños, decidieron obedecer el decreto, bajo cuyo pretexto cesaron inmediatamente de pagar toda clase de exacciones. Como Pollack observa, "estas respuestas contradictorias permiten intuir sobre la falta de unanimidad entre la población indígena de la provincia respecto al asunto y en el caso de San Miguel Totonicapán, muestran que existía un debate abierto sobre el tema entre los líderes del pueblo" (p. 97).

Por su parte, las autoridades reales también se dividieron al respecto. De un lado, el alcalde mayor de Totonicapán, Narciso Mallol, quien había sido nombrado por el gobierno de las cortes y por tanto simpatizaba con las tendencias liberales de sus miembros, decidió obedecer e implementar los decretos, castigando a todos los que se oponían. Por otro lado, el presidente José de Bustamante y el arzobispo Ramón Casaus, junto con las autoridades de Quetzaltenango, temerosos de atizar el descontento entre la mayoría indígena, resolvieron suspender hasta nueva orden la implementación de los decretos. No obstante, Mallol se mantuvo en su postura desafiante, al tiempo que forjaba una alianza con los k'iche's de San Miguel, entre los que se encontraba el principal Atanasio Tzul. En estas circunstancias, el presidente Bustamante, quien veía 
con preocupación la desobediencia de Mallol, ya que según él fomentaba el desorden social entre la mayoría campesina, decidió entablar causa judicial en contra del magistrado provincial con el fin de reemplazarlo. A continuación, Bustamante ordenó que Mallol se retirara a distancia prudencial de la cabecera mientras que Miguel Carrillo, el corregidor de Quetzaltenango, llevaba a cabo la pesquisa de rigor. Sin embargo, tal decisión causó disgusto entre los seguidores de Mallol $y$ en octubre de 1813 una muchedumbre como de 4.000 personas, compuesta de indígenas y ladinos, escoltó a Mallol de vuelta a San Miguel Totonicapán, situación que obligó a Carrillo a regresarse a Quetzaltenango. Por varias semanas, Mallol persistió en su quijotesco empeño. Pero hacia finales del año, tal vez reconociendo lo que a todas luces era una situación insostenible, decidió dimitir de su cargo y salir de la jurisdicción.

$\mathrm{Al}$ analizar este peculiar incidente, Pollack destaca la que considera significativa alianza entre el grupo de líderes k'iche's y Mallol, ya que fueron justamente dichos seguidores del funcionario liberal los que más tarde conformarían el núcleo dirigente del levantamiento de 1820. De otro lado, Pollack cree ver en tal alianza un ejemplo del impacto temprano - al menos dentro de algunos sectores del campesinado indígena- del pensamiento liberal de Cádiz — la aceptación o adhesión a la ideología liberal-, tendencia que parece haber persistido en el pueblo hasta bien entrado el período republicano. Al mismo tiempo, el autor opina que los "sucesos de 1813 - división entre los principales k'iche's y el apoyo popular recibido por una de las facciones - perfila las divisiones entre los maceguales y los principales que se hicieron visibles en 1820" (p. 117).

En el capítulo cuarto, Pollack examina en detalle los sucesos que desembocaron en el levantamiento de julio de 1820. Como se mencionó en la introducción de esta reseña, el asunto central fue el intento de Fernando VII, al regresar de su cautiverio, de reimponer el tributo y, a la vez, la firme decisión de varios grupos de k'iche's de no hacer los pagos. En la provincia de
Totonicapán, la creciente situación de crisis que había sido precipitada por el desplome de la economía regional junto con la crisis de gobierno en la madre patria, vino a ser recrudecida por una serie de calamidades que se desataron justo al momento de anunciarse la reimposición del tributo. Entre ellas, una devastadora epidemia de viruela a mediados de 1815, seguida de una serie de malas cosechas que ocasionaron hambruna aguda en numerosos pueblos y, a mediados de 1816, un terremoto que causó enorme destrucción. Fue en el marco de estas circunstancias de penuria y sufrimiento que las ocurrencias de 1820 narradas en la introducción se desarrollaron. Según Pollack, luego de la supresión de la rebelión, "la lucha política indígena volvió al ámbito municipal, donde había yacido durante la mayor parte del período colonial" (p. 162).

En el último capítulo, Pollack describe las condiciones en Totonicapán durante las dos décadas que siguieron al levantamiento. La evidencia consultada por el autor sugiere fuerte continuidad con respecto al período precedente, ya que durante esos años la crisis económica no menguó y por ende las comunidades k'iche's continuaron en resistencia al pago de impuestos. Otro fenómeno que persistió durante esos años fueron los conflictos entre principales y maceguales al interior de varias de las más importantes comunidades, así como las luchas entre indígenas y ladinos a raíz del intento de formar ayuntamientos unitarios. Y más impactante aún durante este período fue el empeño de la elite ladina de Quetzaltenango por emanciparse de lo que llamaban yugo guatemalteco, proyecto autonomista regional que se había originado hacia finales de 1821 con la anexión de Quetzaltenango a México. Bajo el sistema federal centroamericano, dicho proyecto llegó a fructificar brevemente en 1838 y después en 1848 al funcionar Quetzaltenango como la capital del estado de Los Altos, el sexto de la Federación, el cual estuvo conformado por los departamentos del occidente guatemalteco. Los indígenas de la región, por su parte, 
se opusieron decididamente a la consolidación de tal proyecto pues juzgaban sus políticas desarrollistas liberales como lesivas a su propio anhelo de preservar su integridad cultural e identidad étnica. Es por ello que forjaron alianzas políticas con grupos dirigentes de la ciudad de Guatemala, ya fueran liberales o conservadores, con el propósito de ponerle coto al poderío quetzalteco. La más duradera de estas alianzas fue la forjada a partir de 1840 entre los indígenas y Rafael Carrera, el caudillo ladino campesino que lideró la campaña militar que puso fin al proyecto secesionista quetzalteco. En opinión de Pollack, dicha alianza acabó por recrudecer aún más las divisiones étnicas entre ladinos e indígenas en Los Altos, las cuales persistieron a través del siglo XIX y siguen hoy caracterizando a la sociedad guatemalteca.

En la conclusión, Pollack hace hincapié en el que considera el aspecto más revelador de su investigación, o sea, la indudable capacidad de actuación autónoma de los kiche's de Totonicapán. Afirma que la evidencia presentada a lo largo del texto, "indica que [los indígenas] eran políticos consagrados e inteligentes, que hacían uso de cualesquiera medios disponibles para promover sus objetivos: los recursos legales, el tortuguismo, la violencia y hasta el ofrecimiento de donaciones anuales a la Corona" (p. 208). Y en lo que se refiere al significado histórico del levantamiento de 1820, Pollack concluye que:

...la resistencia indígena a cualquier tipo de tributación, y más tarde a las imposiciones del Estado de Los Altos, contribuyó a derrocar a cuatro gobiernos en un espacio de veinte años. El único intento por transformar este poder de resistencia en una coordinación administrativa continúa más allá del ámbito del pueblo, la breve rebelión de 1820 fue suprimida rápidamente y con ello lo que quizá haya sido el intento más fuerte por crear una modernidad multicultural en Guatemala antes de 1996 (p. 208).
El trabajo de Pollack constituye un valiosísimo aporte al estudio del pasado guatemalteco. El libro representa en particular una importante contribución a lo que se podría llamar "la nueva historia regional" guatemalteca; la cual, desde sus comienzos en la década de 1980, ha tenido como objetivo central visibilizar el papel histórico de los actores subalternos, principalmente el de las comunidades mayas que han habitado la región del altiplano occidental desde tiempo inmemorial, y cuyas vivencias y aportes han sido ignorados por la historiografía nacional (véase Zamora, 1985; Lovell, 1985; Hill, 1992; González, 1994; Taracena, 1997; Grandin, 2000; Reeves, 2006).

Entre los muchos méritos de la obra está el esfuerzo del autor por reinterpretar el levantamiento de 1820 desde una novedosa perspectiva geográfico histórica, la cual le permite reconstruir en gran detalle la enorme complejidad social, económica y política que caracterizaba - y sigue caracterizando- a las comunidades mayas guatemaltecas. Es precisamente la atención al análisis de toda esa abigarrada madeja de conflictos y alianzas entre elites y maceguales, así como entre indígenas y no indígenas, que son factores que influyeron de manera determinante en el levantamiento de 1820, lo que en buena medida distingue el trabajo de Pollack con respecto a estudios previos del episodio (véase Contreras, 1951; Bricker, 1981; McCreery, 1989).

En este sentido, igualmente valioso es el tratamiento de los sucesos dentro de un amplio contexto histórico, aspecto al que los análisis anteriores tampoco habían prestado mayor atención. Particularmente instructivo es el análisis del proceso de "modernización etnizada" que según Pollack se inició en la segunda mitad del siglo XVIII y del cual se derivaron las condiciones socioétnicas y políticas que culminaron en el levantamiento de 1820. Es así como, resultado de esta metodología, el libro de Pollack, más que un sólido examen de una importante sublevación indígena, viene a constituir en realidad un ambicioso estudio de la provincia de Totonicapán durante un momento crucial en su evolución histórica; 
aporte que viene a llenar un importante vacío en la historiografía reciente de la región altense.

Y no menos meritorio también es el esfuerzo de Pollack por fundamentar su investigación en una enorme cantidad de fuentes primarias inéditas, muchas de las cuales recabó en los archivos municipales y eclesiásticos de varias comunidades indígenas de Totonicapán. Dichas fuentes le permiten al autor incorporar a la narrativa los puntos de vista de muchos de los actores indígenas que participaron en el conflicto, lo cual le añade especial realce al trabajo. Esta admirable y exhaustiva labor archivística está complementada por una igualmente sólida base bibliográfica en la literatura secundaria pertinente.

Con todo, algunos de los planteamientos del autor no están, en mi opinión, adecuadamente documentados. Entre ellos se encuentran los presuntos nexos entre los rebeldes de Totonicapán y los líderes liberales y proindependencia de la Ciudad de Guatemala. Aunque los argumentos de Pollack son sugestivos, a mi modo de ver, lo que a este respecto la evidencia presentada en el texto deja claro es que la gran mayoría de indígenas, no solo de Totonicapán sino también los del resto de la región altense, rechazó las reformas liberales del gobierno de las cortes en vista de que entendía que tales innovaciones, aunque supuestamente beneficiosas, representaban en realidad una amenaza frontal a sus intereses económicos y etnopolíticos. Fue entonces sólo una corta minoría - el núcleo rebelde - la que decidió acatar los decretos. Sin embargo, parece claro que el apoyo a tales reformas, más que inspirado en principios liberales, formaba parte de una pragmática estrategia de resistencia que le permitiría a los sublevados justificar su desacato a las órdenes reales. O sea que el levantamiento de 1820, en resumen, debe entenderse ante todo como un movimiento de protesta popular provocado por la que algunos percibían como despiadada inflexibilidad, y otros como perversa mendacidad, por parte de las autoridades fiscales, en un momento de extrema penuria entre las comunidades indígenas. Al decir de James
Scott, "cuando uno no tiene suficiente para comer, uno no paga impuestos de buena gana" (Scott, 1976: 136). Y, por otro lado, la prueba de que no se trataba de una insurrección dirigida a romper los lazos con la madre patria radica en el hecho de que los rebeldes en ningún momento cesaron de jurar su adhesión a la corona y siempre mantuvieron el retrato del monarca cautivo, Fernando VII, en la sala del cabildo. Se trataba entonces de un caso más de protesta colonial en el que los rebeldes solían exclamar, "viva el rey, muera el mal gobierno".

Finalmente, un aspecto que en mi opinión mereció tratamiento y que no recibe consideración en el libro es el de las dimensiones ecológicas de la crisis económica que afligió a los pueblos de Totonicapán alrededor de los años del levantamiento. Esto se trae a colación en este contexto debido a que dicha temática ya ha sido investigada por el geógrafo historiador Thomas Veblen en su estudio pionero sobre el impacto socioecológico de la conquista y colonización española sobre la población indígena de la provincia de Totonicapán (Veblen, 1975). En dicho trabajo, Veblen cita evidencia que apunta hacia una severa crisis agraria en las últimas décadas del período colonial ocasionada fundamentalmente por el adverso impacto que la producción comercial de trigo y lana tuvieron sobre el sistema de producción indígena tradicional. Dichas prácticas, en las que participaban tanto indígenas como no indígenas, acabaron por reducir la cantidad absoluta de tierra apta para el cultivo de milpa y al mismo tiempo produjeron erosión e infertilidad en los valles más productivos de la región. En consecuencia, en los años anteriores al levantamiento de 1820 , la población indígena de Totonicapán ya comenzaba a padecer escasez de tierra y experimentar malas cosechas, todo lo cual a su vez ocasionó un creciente conflicto socioétnico, así como hambruna y destructivos brotes de enfermedades epidémicas. En su descripción de la estructura económica de Totonicapán, Pollack cita de paso la tesis de Veblen (pp. 64, 66), pero omite incorporar los sugestivos hallazgos del estudio a su propio análisis de la crisis económica. Es de esperar 
entonces que futuras investigaciones se ocupen de manera más sistemática de tan relevante aspecto de la experiencia colonial guatemalteca.

Desde luego, estos mínimos reparos en nada le restan valor al aporte de Pollack, el cual indudablemente representa un paso adelante en la importante tarea de forjar una historiografía en la que figuren las experiencias y logros no solo de los sectores privilegiados, sino también los de los sectores populares de Guatemala.

\section{Bibliografía}

Bricker, Victoria (1981), The Indian Christ, the Indian King: The Historical Substrate of Maya Myth and Ritual, Austin: University of Texas Press.

Contreras, Daniel (1951), Una rebelión indígena en el partido de Totonicapán en 1820: el Indio y la independencia, Guatemala: Imprenta Universitaria.

González, Jorge H. (1994), "A History of Los Altos, Guatemala: A Study of Regional Conflict and National Integration, 1750-1885", en Tesis Doctoral, Tulane University.

Grandin, Greg (2000), The Blood of Guatemala: A History of Race and Nation, Durham \& London: Duke University Press.

Hill, Robert M. (1992), Colonial Cakchiquels: Highland Maya Adaptation to Spanish Rule 1600-1700, New York: Harcourt Brace Jovanovich, Publishers.
Lovell, George (1985), Conquest and Survival in Colonial Guatemala: A Historical Geography of the Cuchumatán Highlands, 1500-1821, Montreal: McGill-Queen's University Press.

McCreery, David (1989), "Atanasio Tzul, Lucas Aguilar, and the Indian Kingdom of Totonicapán", en Judy Ewell y William Beezley, eds. The Human Tradition in Latin America: The Nineteenth Century, Wilmington: Scholarly Resources Inc.

Reeves, René (2006), Ladinos with Ladinos, Indians with Indians: Land, Labor, and Regional Ethnic Conflict, Stanford: Stanford University Press.

Scott, James C. (1976), The Moral Economy of the Peasant, New Haven: Yale University Press.

Taracena, Arturo (1997), Invención criolla, sueño ladino, pesadilla indígena: Los Altos de Guatemala: de región a estado, 1740-1850, Antigua, Guatemala: CIRMA.

Veblen, Thomas (1975), The Ecological, Cultural, and Historical Bases of Forest Preservation in Totonicapán, Guatemala, Berkeley: University of Berkeley.

Zamora Acosta, Elías (1985), Los Mayas de las tierras altas en el siglo XVI: Tradición y cambio en Guatemala, Sevilla: Diputación Provincial de Sevilla.

Jorge González Alzate Phd, Tulane University Investigador Independiente, Washington, USA jhalzate@comcast.net 